TITLE:

\title{
Rhodium-Catalyzed Dehydrogenative Borylation of Aliphatic Terminal Alkenes with Pinacolborane.
}

\section{$\operatorname{AUTHOR}(S)$ :}

Morimoto, Masao; Miura, Tomoya; Murakami, Masahiro

\section{CITATION:}

Morimoto, Masao ...[et al]. Rhodium-Catalyzed Dehydrogenative Borylation of Aliphatic Terminal Alkenes with Pinacolborane.. Angewandte Chemie - International Edition 2015, 54(43): 12659-12663

\section{ISSUE DATE:}

2015-10-19

URL:

http://hdl.handle.net/2433/203160

\section{RIGHT:}

This is the peer reviewed version of the following article: Morimoto, M., Miura, T. and Murakami, M. (2015), RhodiumCatalyzed Dehydrogenative Borylation of Aliphatic Terminal Alkenes with Pinacolborane. Angew. Chem. Int. Ed., 54: 12659-12663, which has been published in final form at http://dx.doi.org/10.1002/anie.201506328. This article may be used for non-commercial purposes in accordance with Wiley Terms and Conditions for Self-Archiving.; The full-text file will be made open to the public on 2 September 2016 in accordance with publisher's 'Terms and Conditions for SelfArchiving'.; この論文は出版社版でありません。引用の際には出版社版をご確認ご利用ください。; This is not the published version. Please cite only the published version. 


\title{
Rhodium-Catalyzed Dehydrogenative Borylation of Aliphatic Terminal Alkenes with Pinacolborane ${ }^{\star \star}$
}

\author{
Masao Morimoto, Tomoya Miura, ${ }^{*}$ and Masahiro Murakami
}

\begin{abstract}
Aliphatic terminal alkenes react with pinacolborane at ambient temperature to afford dehydrogenative borylation compounds as the major product when ${ }^{\mathrm{P}} \mathrm{Pr}$-Foxap is used as the ligand of a cationic rhodium(I) in the presence of norbornene, which acts as the sacrificial hydrogen acceptor. The reaction is applied to the one-pot syntheses of aldehydes and homoallylic alcohols from aliphatic terminal alkenes.
\end{abstract}

The hydroboration of alkenes with borane reagents giving the corresponding alkylboranes is a fundamental textbook reaction. The use of transition metal catalysts makes it possible to use dialkoxyborane reagents $\left[\mathrm{HB}(\mathrm{OR})_{2}\right]$ for the hydroboration under mild conditions. ${ }^{[1]}$ A variety of transition metal complexes such as rhodium(I), ${ }^{[2]}$ iridium(I), ${ }^{[3]}$ ruthenium(II), ${ }^{[4]}$ iron(0), ${ }^{[5]}$ and cobalt $(\mathrm{I})^{[6]}$ catalyze the hydroboration of terminal alkenes with pinacolborane (HBpin), forming alkyl pinacolboronates in a regioselective way [Figure 1. (a)]. Interestingly, the dehydrogenative borylation competes with the hydroboration in some cases to afford alkenyl pinacolboronates as the major product. $^{[7-9]}$ For example, Masuda et al. reported that the reaction of styrene with HBpin in the presence of neutral $[\mathrm{RhCl}(\mathrm{cod})]_{2}$ gave the dehydrogenative borylation product along with a small amount of the hydroboration products. ${ }^{[8 a, c]}$ Concurrently, ethylbenzene was generated in a same amount with styryl pinacolboronate, showing that a half of styrene was used as the hydrogen acceptor. Therefore, an excess amount of styrene was required. Moreover, the substrates for the successful dehydrogenative borylation are limited to arylethenes and alkoxyethenes. There is no facile method to obtain the dehydrogenative borylation compounds from aliphatic termina alkenes and HBpin. ${ }^{[10,11]}$ Now, we report a rhodium(I)-catalyzed

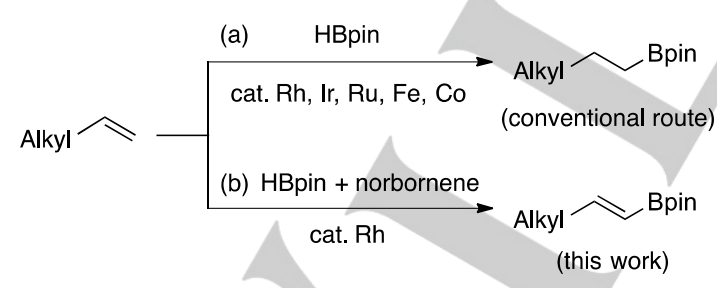

Figure 1. Two pathways of the borylation reaction of aliphatic terminal alkenes with pinacolborane (HBpin).

[*] Dr. M. Morimoto, Dr. T. Miura, Prof. Dr. M. Murakam Department of Synthetic Chemistry and Biological Chemistry Kyoto University, Katsura, Kyoto 615-8510 (Japan) E-mail: tmiura@sbchem.kyoto-u.ac.jp murakami@sbchem.kyoto-u.ac.jp

[**] This work was supported in part by a Grant-in-Aid for Scientific Research (S) from MEXT and the ACT-C program of the JST. We thank Prof. Keiji Morokuma, Dr. Travis V. Harris, and Dr. W. M. C. Sameera for enriching discussion. M. Morimoto thanks the JSPS for Young Scientists for a Research Fellowship.

Supporting information for this article is given via a link at the end of the document. reaction of aliphatic terminal alkenes with HBpin, which produce preferentially dehydrogenative borylation compounds [Figure 1. (b)]. The use of ${ }^{i} \mathrm{Pr}$-Foxap as the ligand of cationic rhodium(I) and norbornene as the sacrificial hydrogen acceptor is the key for the dehydrogenative borylation. Hydroboration of terminal alkynes with HBpin is a straightforward and reliable method for the stereoselective preparation of $(E)$-alkenyl pinacolboronates. ${ }^{[12]}$ Even $(Z)$-isomers have become accessible by hydroboration of terminal alkynes. ${ }^{[13]}$ Sometimes, overreduction of the alkyne to give saturated diboronates compounds, ${ }^{[14]}$ along with issues of regioselectivity, complicates this route. The attractiveness of the dehydrogenative borylation is the use of readily available terminal alkenes as starting materials instead of terminal alkynes.

Initially, 4-phenylbut-1-ene (1a, 1.0 equiv) was subjected to the reaction with $\mathrm{HBpin}$ (2, 1.7 equiv) in the presence of $\left[\mathrm{Rh}(\mathrm{cod})_{2}\right] \mathrm{BF}_{4}{ }^{[2 \mathrm{c}]}$ and norbornene (nbe, 2.3 equiv) as the

Table 1: Optimization of reaction conditions for the dehydrogenative borylation of 4-phenylbut-1-ene (1a) with HBpin (2). ${ }^{[a]}$

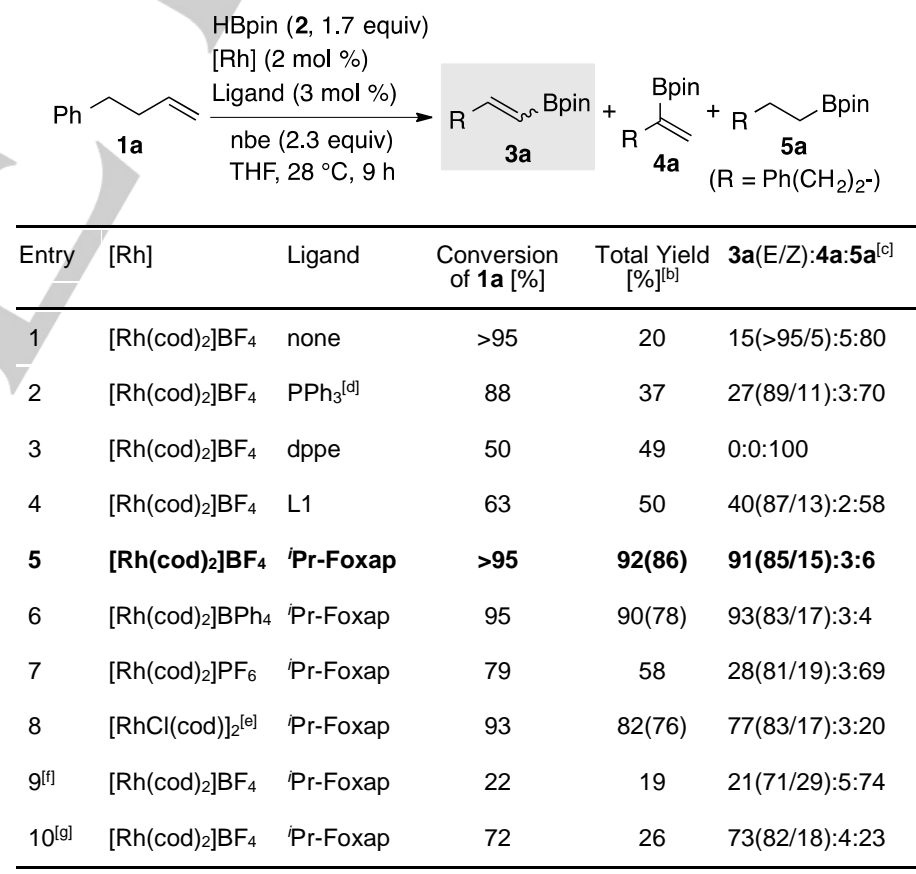

[a] On a $0.50 \mathrm{mmol}$ scale. [b] Total yield of $\mathbf{3}, \mathbf{4}$, and $\mathbf{5}$ detemined by GC. In parentheses, total yield after chromatographic purification. [c] Product ratio determined by GC. [d] Using $\mathrm{PPh}_{3}(6 \mathrm{~mol} \%)$. [e] Using $[\mathrm{RhCl}(\mathrm{cod})]_{2}(1 \mathrm{~mol} \%)$ [f] Using norbornadiene (2.3 equiv) instead of nbe. [g] Using styrene (2.3 equiv) instead of nbe.

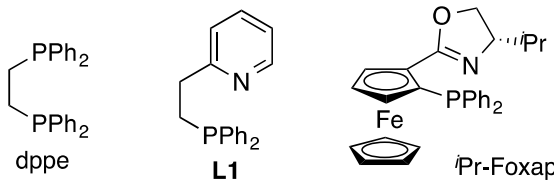


sacrificial hydrogen acceptor (Table 1, entry 1). After the reaction mixture was stirred at $28{ }^{\circ} \mathrm{C}$ for 9 hours, a mixture of the dehydrogenative borylation products $\mathbf{3} \mathbf{a}$ and $\mathbf{4 a}$, and the hydroboration product $\mathbf{5 a}$ was formed in a ratio of $\mathbf{3 a}: \mathbf{4 a}: 5 \mathbf{a}=$ $15: 5: 80$, albeit in $20 \%$ total yield. The hydrogenation of $1 \mathbf{a}$ also occurred as a side reaction. Next, various ligands were examined using $\left[\mathrm{Rh}(\mathrm{cod})_{2}\right] \mathrm{BF}_{4}$ as the catalyst precursor. Whereas the use of simple phosphine ligands such as $\mathrm{PPh}_{3}$ and dppe yielded preferentially the hydroboration product $\mathbf{5 a}$ (entries 2 and 3), P-N bidentate ligand (L1) gave a better product

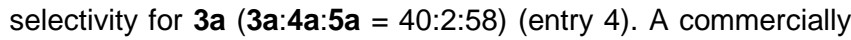
available P-N bidentate ligand, ${ }^{i}$ Pr-Foxap, ${ }^{[15]}$ exhibited a dramatic effect to favor the formation of $\mathbf{3 a}^{[16]}$ After chromatographic purification, the product $\mathbf{3 a}$ was obtained as a mixture with $\mathbf{4 a}$ and $\mathbf{5 a}(\mathbf{3 a : 4 a : 5 a}=91: 3: 6)$ in $86 \%$ total yield (entry 5). ${ }^{[17]}$ The $E / Z$ ratio of $\mathbf{3 a}$ was $85: 15$. The counterions of rhodium(I) complexes also affected the product selectivity. The tetraphenylborate complex $\left[\mathrm{Rh}(\mathrm{cod})_{2}\right] \mathrm{BPh}_{4}$ showed a comparable product selectivity (3a:4a:5a $=93: 3: 4)$, but the hexafluorophosphate complex $\left[\mathrm{Rh}(\mathrm{cod})_{2}\right] \mathrm{PF}_{6}$ resulted in a lower product selectivity (3a:4a:5a $=28: 3: 69)$ (entries 6 and 7). While the neutral complex $[\mathrm{RhCl}(\mathrm{cod})]_{2}$ is known as the effective precursor for the dehydrogenative borylation of styrene, ${ }^{[8 a, c]}$ it gave a result inferior to $\left[\mathrm{Rh}(\mathrm{cod})_{2}\right] \mathrm{BF}_{4}$ in terms of both yield and product selectivity (entry 8). Furthermore, the choice of hydrogen acceptor was important. When norbornadiene or styrene was used as the hydrogen acceptor, the yield of $\mathbf{3 a}$ markedly decreased (entries 9 and 10). ${ }^{[18]}$

Although it is difficult to explain the reaction pathway leading to alkenyl boronate $\mathbf{3}$ from aliphatic terminal alkene $\mathbf{1}$ and HBpin (2), a possible mechanism is depicted in Scheme 1. It is similar to the one proposed by Hartwig et al. for the iridium(I)-catalyzed dehydrogenative silylation using norbornene as the hydrogen acceptor. ${ }^{[19]}$ Oxidative addition of the $\mathrm{B}-\mathrm{H}$ bond of $\mathbf{2}$ onto rhodium(I) affords the boryl(hydride)rhodium species $A$. Subsequent insertion of the alkene $\mathbf{1}$ into the Rh-B bond of $\mathbf{A}$ takes place to give the alkyl-rhodium intermediate $\mathbf{B}$. The initial conformer undergoes rotation along the $\mathrm{C}-\mathrm{C}$ bond axis to form the other conformer $\mathbf{C}$. Then, syn $\beta$-hydride elimination furnishes the $(E)$-isomer of alkenyl boronate 3 . (Dihydride)rhodium species $\mathbf{D}$ reacts with norbornene to

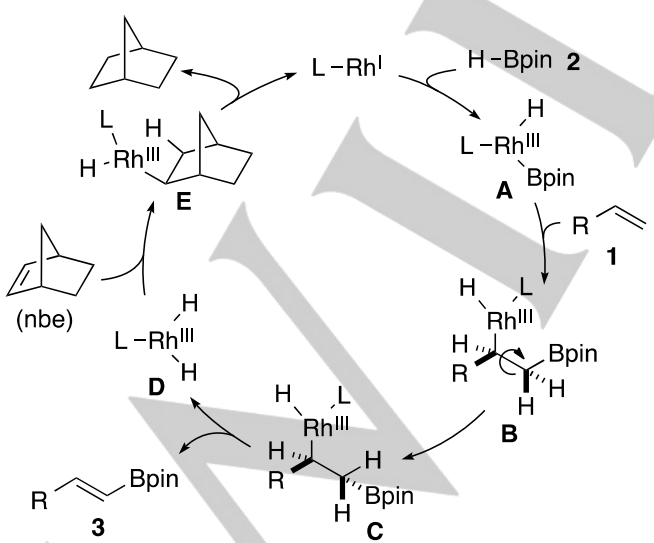

generate an active rhodium(I) species together with norbornane. ${ }^{[17,20]}$ The strained structure of norbornene enhances the reactivity toward $\mathbf{D}^{[18]}$ Therefore, hydroboration of norbornene is preferred over the alkenyl pinacolboronate $\mathbf{3 a}$.

The following experiments were carried out in order to obtain mechanistic insights into the stereoselectivity. First, the rhodium(I)-catalyzed reaction of 4-phenylbut-1-ene (1a) with HBpin (2) was monitored by GC after $20 \mathrm{~min}$ (Eq 1). The $E / Z$ ratio of $\mathbf{3 a}$ was $74: 26$ at $18 \%$ conversion of $\mathbf{1 a}$. Thus, the $E / Z$ ratio of $\mathbf{3 a}$ changed during the reaction (vs. 9 hours; Table 1 , entry 5).

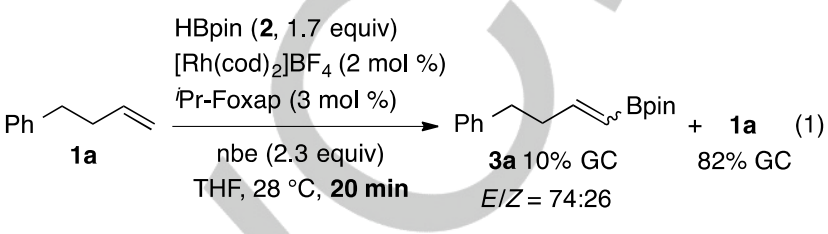

Secondly, the purified ( $Z$ )-isomer of $\mathbf{3 a}$ was subjected to the standard reaction conditions using oct-1-ene (1c) as a substrate (Eq 2). The $E / Z$ isomerization of $\mathbf{3 a}$ took place to give an $E / Z=$ $57: 43$ mixture. Based on these results, the stereochemistry seems to be subject to thermodynamics rather than kinetics.

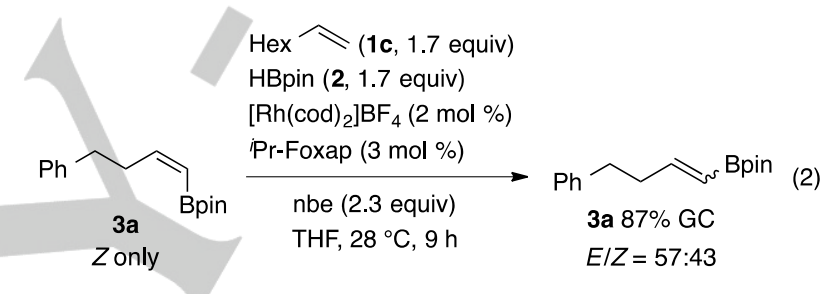

A variety of terminal alkenes $\mathbf{1}$ were subjected to the dehydrogenative borylation with HBpin (2) by using a combination of $\left[\mathrm{Rh}(\mathrm{cod})_{2}\right] \mathrm{BF}_{4} / \mathrm{Pr}$-Foxap and norbornene (Table 2). Mono-substituted alkenes $\mathbf{1 b}-\mathbf{f}$ readily reacted with 2 to afford the corresponding alkenyl pinacolboronates $\mathbf{3 b}-\mathbf{f}$ with good yields, product selectivities, and E/Z ratios (entries 1-5), whereas the reactions of 3-tert-butylprop-1-ene $(\mathbf{1 g})$ and cyclohexylethene (1h) were rather sluggish, probably owing to the steric hindrance (entries 6 and 7). Functional groups such as siloxy, chloro, methoxycarbonyl, and epoxy groups were tolerated in the alkyl chain under the reaction conditions (entries 8-13). The reaction of 1,1- and 1,2-disubstituted alkenes such as 1,1-diethylethene and cyclohexene failed to give the desired alkenyl pinacolboronates. ${ }^{[21]}$ Therefore, in the case of 2methylhexa-1,5-diene (10) including 1,1-disubstituted alkene moiety, only the terminal mono-substituted alkene moiety underwent the dehydrogenative borylation to afford monoborylated product 30 (entries 14). Similarly, 4,8-dimethylnona1,7-diene (1p) produces selectively mono-borylated product $3 p$ (entry 15). 1,1-Dimethylbuta-1,3-diene (1q) was also a suitable substrate to give the corresponding dienylboronate $\mathbf{3 q}$ with high product selectivity and $E / Z$ ratio (entry 16$)$. Allyltriphenylsilane (1r) and 4-methoxystyrene (1s) successfully participated in this reaction (entries 17 and 18 ). The $(E)$-isomer was exclusively formed with $3 \mathbf{s}$. 
Table 2: $\mathrm{Rh}^{\prime}$-catalyzed dehydrogenative borylation of various terminal alkenes 1 with HBpin (2). ${ }^{\text {a] }}$

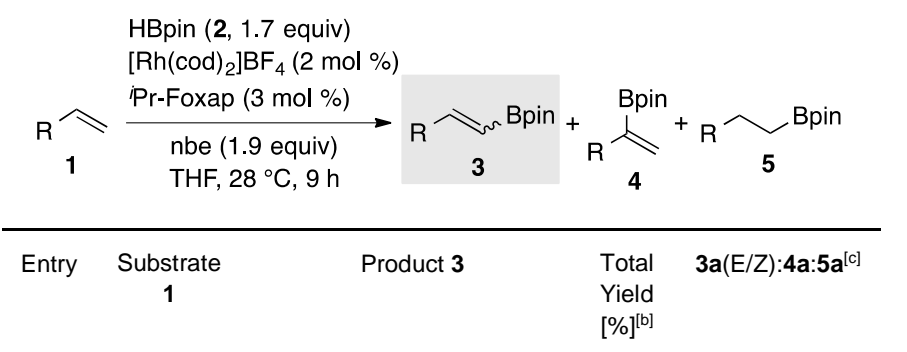

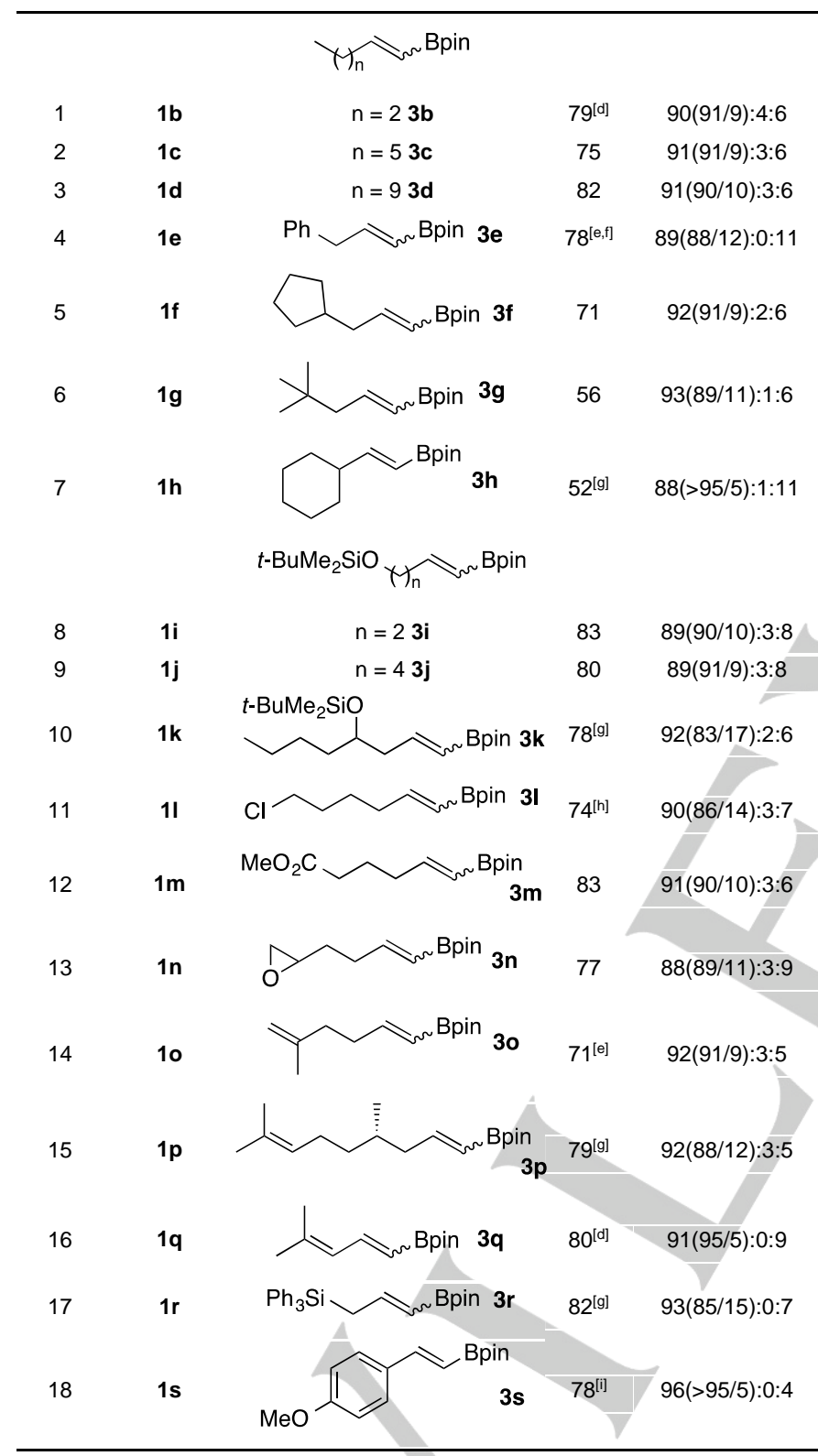

[a] On a $0.50 \mathrm{mmol}$ scale. [b] Total yield of 3, 4, and $\mathbf{5}$ after chromatographic purification. [c] Product ratio determined by ${ }^{1} \mathrm{H}$ NMR analysis. [d] NMR yield. [e] Using nbe (2.3 equiv). [f] Containing 2-cinnamyl-Bpin (4\%). [g] Using nbe (1.7 equiv). [h] Using nbe (2.5 equiv). [i] Containing 1-(4-methoxyphenyl)ethylBpin (2\%).
The resulting alkenyl pinacolboronates were useful intermediates in organic synthesis. ${ }^{[1 \mathrm{~b}]}$ Thus, we examined onepot two-step transformations via the formation of alkenyl boronates, saving time and solvents required for a workup/purification procedure. After volatile materials in the reaction mixture of aliphatic terminal alkene 1a with HBpin (2) were removed under reduced pressure, aqueous THF solution of sodium perborate was directly added to the residue including alkenyl pinacolboronate $\mathbf{3 a}$. Oxidation of $\mathbf{3 a}$ occurred to form the corresponding aldehyde $\mathbf{6}$ in $60 \%$ isolated yield based on $\mathbf{1 a}$ (Scheme 2). Formally, this one-pot reaction achieved antiMarkovnikov oxidation of terminal alkenes at ambient temperature, ${ }^{[22]}$ complementing the Wacker-Tsuji oxidation by palladium catalyst. Furthermore, it avoids the need for two oxidation steps to convert a hydroboration product (alkyl boronate) of an alkene into an aldehyde.

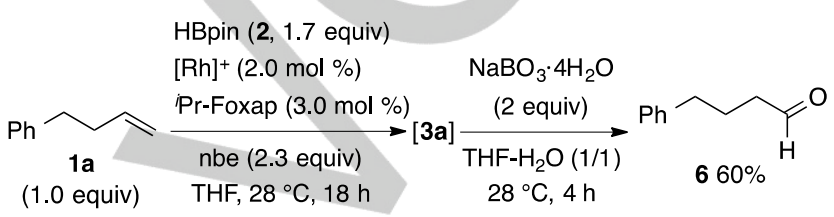

Scheme 2. One-pot synthesis of aldehydes from terminal alkenes.

We have recently reported an enantioselective synthesis of anti-homoallylic alcohols from terminal alkynes, HBpin, and aldehydes via the formation of alkenyl pinacolboronates, which act as $\gamma$-substituted allylboron species. ${ }^{[23]}$ Thus, the residue including alkenyl pinacolboronate $\mathbf{3 b}$ was treated with benzaldehyde ( 7$)$ in the presence of $\left[\operatorname{Ir}(\operatorname{cod})_{2}\right] \mathrm{BF}_{4} / \mathrm{PCy}_{3}$ and $(R)$ TRIP in 1,2-dichloroethane (DCE). Anti-homoallylic alcohol 8 was obtained with high diastereo- and enantioselectivities (Scheme 3). The above-mentioned reactions provide efficient methods to directly functionalize aliphatic terminal alkenes in one pot.

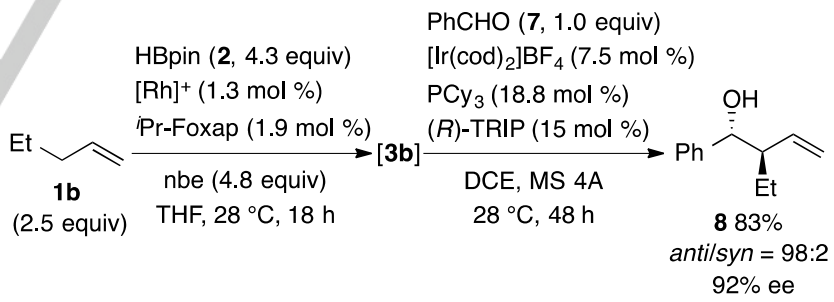

Scheme 3. One-pot synthesis of homoallylic alcohols from terminal alkenes. $(R)$-TRIP = (R)-3,3'-Bis(2,4,6-triisopropylphenyl)-1,1'-binaphthyl-2,2'-diyl hydrogenphosphate.

In summary, we have disclosed that a combined use of a cationic rhodium(I) complex, ${ }^{i}$ Pr-Foxap, and norbornene enables the facile preparation of alkenyl pinacolboronates from aliphatic terminal alkenes and HBpin at ambient temperature. Since terminal alkenes are more easily accessible and often more desirable starting materials than terminal alkynes, the reaction represents an interesting alternative to alkyne hydroboration. Based upon the dehydrogenative borylation reaction, the onepot syntheses of aldehydes and homoallylic alcohols starting from terminal alkenes have also been realized. Further studies 
to elucidate the mechanism of this reaction and to expand its utility are in progress.

Keywords: alkenyl boronate $\cdot$ borylation $\bullet$ pinacolborane $\bullet$ rhodium $\bullet$ terminal alkenes

[1] a) C. M. Crudden, D. Edwards, Eur. J. Org. Chem. 2003, 4695; b) Boronic Acids: Preparation and Applications in Organic Synthesis, Medicine and Materials, 2nd ed. (Ed.: D. G. Hall), Wiley-VCH, Weinheim, 2011.

[2] a) S. Pereira, M. Srebnik, J. Am. Chem. Soc. 1996, 118, 909; b) S Pereira, M. Srebnik, Tetrahedron Lett. 1996, 37, 3283; c) C. M Crudden, Y. B. Hleba, A. C. Chen, J. Am. Chem. Soc. 2004, 126, 9200; d) D. R. Edwards, C. M. Crudden, K. Yam, Adv. Synth. Catal. 2005, 347, 50; e) M. A. Reichle, B. Breit, Angew. Chem. Int. Ed. 2012, 51 5730; Angew. Chem. 2012, 124, 5828.

[3] Y. Yamamoto, R. Fujikawa, T. Umemoto, N. Miyaura, Tetrahedron 2004, 60, 10695. See also Ref. [2c].

[4] A. Caballero, S. Sabo-Etienne, Organometallics, 2007, 26, 1191

[5] a) L. Zhang, D. Peng, X. Leng, Z. Huang, Angew. Chem. Int. Ed. 2013, 52, 3676; Angew. Chem. 2013, 125, 3764; b) J. V. Obligacion, P. J. Chirik, Org. Lett. 2013, 15, 2680; c) M. D. Greenhalgh, S. P. Thomas Chem. Commun. 2013, 49, 11230; d) K.-N. T. Tseng, J. W. Kampf, N. K. Szymczak, ACS Catal. 2015, 5, 411.

[6] a) J. V. Obligacion, P. J. Chirik, J. Am. Chem. Soc. 2013, 135, 19107 b) L. Zhang, Z. Zuo, X. Wan, Z. Huang, J. Am. Chem. Soc. 2014, 136, 15501.

[7] For a recent review, see: S. J. Geier, S. A. Westcott, Rev. Inorg. Chem. 2015, 35, 69

[8] For dehydrogenative borylation with HBpin, see: a) M. Murata, S Watanabe, Y. Masuda, Tetrahedron Lett. 1999, 40, 2585; b) C. M. Vogels, P. G. Hayes, M. P. Shaver, S. A. Westcott, Chem. Commun 2000, 51; c) M. Murata, K. Kawakita, T. Asana, S. Watanabe, Y. Masuda, Bull. Chem. Soc. Jpn. 2002, 75, 825.

[9] For dehydrogenative borylation with catecholborane and other borane reagents, see: a) J. M. Brown, G. C. Lloyd-Jones, J. Chem. Soc., Chem. Commun. 1992, 710; b) K. Burgess, W. A. Van der Donk, S. A Westcott, T. B. Marder, R. T. Baker, J. C. Calabrese, J. Am. Chem. Soc. 1992, 114, 9350; c) S. A. Westcott, T. B. Marder, R. T. Baker, Organometallics 1993, 12, 975; d) J. M. Brown, G. C. Lloyd-Jones, J. Am. Chem. Soc. 1994, 116, 866; e) D. H. Motry, A. G. Brazil, M. R. Smith, III. J. Am. Chem. Soc. 1997, 119, 2743; f) D. E. Kadlecek, P. J. Carroll, L. G. Sneddon, J. Am. Chem. Soc. 2000, 122, 10868; g) M. Gerdin, C. Moberg, Org. Lett. 2006, 8, 2929; h) T. Ohmura, Y. Takasaki, H. Furukawa, M. Suginome, Angew. Chem. Int. Ed. 2009, 48, 2372; Angew. Chem. 2009, 121, 2408; i) N. Iwadate, M. Suginome, Chem. Lett. 2010, 39, 558

[10] For the synthesis of alkenyl pinacolboronates from alkenes using B $_{2}$ pin $_{2}$, see: a) R. B. Coapes, F. E. S. Souza, R. L. Thomas, J. J. Hall, T. B. Marder, Chem. Commun. 2003, 614; b) V. J. Olsson, K. J. Szabó, Angew. Chem. Int. Ed. 2007, 46, 6891; Angew. Chem. 2007, 119, 7015; c) T. Kikuchi, J. Takagi, T. Ishiyama, N. Miyaura, Chem. Lett. 2008, 37, 664; d) I. A. I. Mkhalid, R. B. Coapes, S. N. Edes, D. N. Coventry, F. E. S. Souza, R. L. Thomas, J. J. Hall, S.-W. Bi, Z. Lin, T. B. Marder, Dalton Trans. 2008, 1055; e) N. Selander, B. Willy, K. J. Szabó, Angew. Chem. Int. Ed. 2010, 49, 4051; Angew. Chem. 2010, 122, 4145; f) A. Kondoh, T. F. Jamison, Chem. Commun. 2010, 46 907; g) J. Takaya, N. Kirai, N. Iwasawa, J. Am. Chem. Soc. 2011, 133, 12980; h) N. Kirai, S. Iguchi, T. Ito, J. Takaya, N. Iwasawa, Bull. Chem Soc. Jpn. 2013, 86, 784
[11] For another synthetic route to alkenyl pinacolboronates from terminal alkenes via olefin cross-metathesis with vinyl-Bpin, see: a) C. Morrill, R. H. Grubbs, J. Org. Chem. 2003, 68, 6031; b) R. Hemelaere, F. Carreaux, B. Carboni, J. Org. Chem. 2013, 78, 6786; c) E. T. Kiesewetter, R. V. O'Brien, E. C. Yu, S. J. Meek, R. R. Schrock, A. H. Hoveyda, J. Am. Chem. Soc. 2013, 135, 6026; d) B. L. Quigley, R. H. Grubbs, Chem. Sci. 2014, 5, 501.

[12] a) C. E. Tucker, J. Davidson, P. Knochel, J. Org. Chem. 1992, 57 3482; b) S. Pereira, M. Srebnik, Organometallics 1995, 14, 3127; c) K. Shirakawa, A. Arase, M. Hoshi, Synthesis 2004, 1814; d) H. E. Ho, N. Asao, Y. Yamamoto, T. Jin, Org. Lett. 2014, 16, 4670.

[13] a) T. Ohmura, Y. Yamamoto, N. Miyaura, J. Am. Chem. Soc. 2000, 122, 4990; b) C. Gunanathan, M. Hölscher, F. Pan, W. Leitner, J. Am. Chem. Soc. 2012, 134, 14349; c) J. V. Obligacion, J. M. Neely, A. N. Yazdani, I. Pappas, P. J. Chirik, J. Am. Chem. Soc. 2015, 137, 5855.

[14] K. Endo, M. Hirokami, T. Shibata, Synlett 2009, 1331 and references cited therein.

[15] For a review, see: Y. Miyake, Y. Nishibayashi, S. Uemura, Synlett 2008 , 1747

[16] When the reaction of $1 \mathbf{a}$ with 2 was conducted using (rac)-[2-(oxazolin2'-yl)ferrocenyl]diphenylphosphine (the ${ }^{i} \mathrm{Pr}$ group of ${ }^{i} \mathrm{Pr}$-Foxap is lacking) in place of ${ }^{i}$ Pr-Foxap, the yield of $\mathbf{3 a}$ significantly decreased. The result suggests that the bulkiness of the 'Pr group would be one of the important factors.

[17] Norbornane (ca. 83\%), 2-norbornyl pinacolboronate (ca. 46\%), and butylbenzene (ca. 3\%) were also formed (GC yield).

[18] When the reaction was conducted in the absence of norbornene, no alkenyl pinacolboronate $\mathbf{3 a}$ was formed. The hydroboration product $\mathbf{5 a}$ and the diboration product $9 \mathrm{a}$ were formed in $41 \%$ and $44 \%$ yields, respectively. These results indicate that norbornene plays a crucial role of inhibiting over-reduction of $\mathbf{3 a}$. When cyclohexene was used in place of norbornene, it was too unreactive to act as the hydrogen acceptor, giving $\mathbf{5 a}$ and $\mathbf{9 a}$ as the major products.

HBpin (2, 1.7 equiv)

$\left[\mathrm{Rh}(\mathrm{cod})_{2}\right] \mathrm{BF}_{4}(2 \mathrm{~mol} \%)$

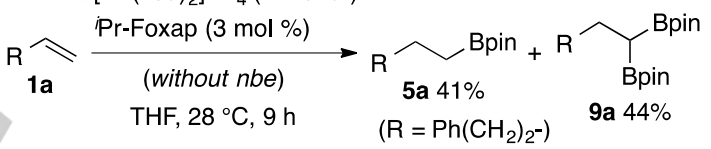

[19] C. Cheng, E. M. Simmons, J. F. Hartwig, Angew. Chem. Int. Ed. 2013 52, 8984; Angew. Chem. 2013, 125, 9154.

[20] For another possible mechanism involving insertion of norbornene into the $\mathrm{Rh}-\mathrm{H}$ bond of $\mathbf{A}$ followed by the sequential insertion of the alkene $\mathbf{1}$ into the Rh-B bond, see: Ref. [8c]

[21] When the reaction of $\alpha$-methylstyrene was carried out under modified reaction conditions [HBpin (2, 2.0 equiv), nbe (1.0 equiv), $\left[\mathrm{Rh}(\mathrm{cod})_{2}\right] \mathrm{BF}_{4}(2 \mathrm{~mol} \%),{ }^{i} \mathrm{Pr}$-Foxap (3 mol \%), THF $\left.(2 \mathrm{M}), 35^{\circ} \mathrm{C}, 6 \mathrm{~h}\right]$, the dehydrogenative borylation product and the hydroboration product were formed in $62 \%$ and $29 \%$ NMR yields, respectively.

[22] For recent examples on the synthesis of aldehydes from terminal alkenes, see: a) G.-Q. Chen, Z.-J. Xu, C.-Y. Zhou, C.-M. Che, Chem Commun. 2011, 47, 10963; b) A. D. Chowdhury, R. Ray, G. K. Lahiri Chem. Commun. 2012, 48, 5497; c) Z. K. Wickens, K. Skakuj, B. Morandi, R. H. Grubbs, J. Am. Chem. Soc. 2014, 136, 890; Review: d) J. J. Dong, W. R. Browne, B. L. Feringa, Angew. Chem. Int. Ed. 2015 54, 734; Angew. Chem. 2015, 127, 744. See also Ref. [2d].

[23] T. Miura, Y. Nishida, M. Morimoto, M. Murakami, J. Am. Chem. Soc 2013, 135, 11497 
Entry for the Table of Contents (Please choose one layout)

\section{COMMUNICATION}

$$
\text { Alkyl } \curvearrowright+\text { HBpin } \underset{\substack{\text { norbornene } \\ 28^{\circ} \mathrm{C}}}{[\mathrm{Rh}]^{+/ \text {Pr-Foxap }}} \text { Alkyl } \text { Bpin }
$$

Aliphatic terminal alkenes react with pinacolborane at ambient temperature in the presence of $\left[\mathrm{Rh}(\mathrm{cod})_{2}\right] \mathrm{BF}_{4} / \mathrm{Pr}$-Foxap and norbornene to produce dehydrogenative borylation compounds as the major product. The reaction is applied to the one-pot syntheses of aldehydes and homoallylic alcohols from aliphatic terminal alkenes.
M. Morimoto, T. Miura, ${ }^{\star}$ M. Murakami*

\section{Page No. - Page No.}

Rhodium-Catalyzed Dehydrogenative Borylation of Aliphatic Terminal Alkenes with Pinacolborane 